\title{
Las urbanizaciones multifamiliares cerradas y su entorno urbano: una nueva geografía simbólica en la ciudad de Cali (Colombia)
}

\author{
Francisco Adolfo García. Universidad del Valle, Cali, Colombia. \\ María del Pilar Peralta. Universidad del Valle, Cali, Colombia.
}

RESUMEN | Una de las dimensiones menos exploradas del surgimiento y consolidación de los denominados condominios cerrados en América Latina ha sido la relación que establecen con su espacio exterior de proximidad. De ahí que sea pertinente reflexionar acerca de cómo los nuevos residentes de esas vecindades, en particular de las denominadas Urbanizaciones Multifamiliares Cerradas (UMC), la mayoría perteneciente a las clases medias emergentes, ordenan y representan su barrio a partir de sus propias prácticas espaciales, experiencias subjetivas e interacción con el medioambiente urbano circundante. Para tal fin, se ha tomado como punto de partida los términos "espacio privatizado particularizado" y "beneficios simbólicos esperados", este último a través del análisis de "mapas cognitivos". Sobre tal base se ha realizado una investigación de tipo etnográfico, la cual se llevó a cabo en un barrio de nueva creación de la ciudad de Cali (Colombia) en el año 2013.

PALABRAS ClAVE | barrios cerrados, espacio público, imaginario urbano.

ABSTRACT | The relation between gated communities in Latin America and their external spaces of proximity has been one of the least explored dimensions since their emergence until their consolidation; hence it is necessary to pay attention to this issue and reflect on how most of the new neighbors of these communities -particularly of Multifamily Gated Housings (MGH's)- belonging to the new middle class, organize and imagine their neighborhood from their own spatial practices, subjective experiences and interaction with the urban environment. This paper is based on an ethnographical research carried out in a new neighborhood of the city of Cali (Colombia) in 2013, where the concepts of "privatized space" and "expected symbolic benefits", the latter through the analysis of "cognitive maps", have been taken as essential bases for this article.

KEY WORDS | gated communities, public space, urban imaginary. 


\section{Introducción}

En el informe elaborado por Naciones Unidas-Hábitat, El estado de las ciudades en América Latina y el Caribe 2012. Rumbo a una nueva transición urbana (onUHabitat, 2012), se señalan muchos de los problemas y obstáculos que han de enfrentar las ciudades latinoamericanas en la actualidad. Uno de ellos es el alto grado de segregación y fragmentación socioespacial que sufren. Precisamente en ese informe, y en orden a explicar tal fenómeno, se establece una relación directa entre el modo habitacional basado en condominios cerrados y la frágil provisión de espacio urbano de proximidad, así como la apropiación poco intensiva de este último por sus residentes. Esta circunstancia está fomentando lo que Saskia Sassen (2010) denomina urban gating y que se refiere a la tendencia global hacia el enclaustramiento en la producción y apropiación de los espacios tanto privados como - muy especialmente- los públicos. Ejemplo de ello serían las residencias multifamiliares cerradas latinoamericanas destinadas a los estratos medios y altos, por cuanto están contribuyendo a la inconexión de espacios y áreas de la ciudad y fomentando la constitución de protoislas urbanas que dificultan el contacto entre individuos y grupos diversos (Janoschka, 2002; Roitman, 2003; Svampa, 2001). Como bien afirma Sennet (1978), "el amor al ghetto, particularmente al ghetto de clase media, niega a la persona la oportunidad de enriquecer sus percepciones, su experiencia, y de aprender la más valiosa de todas las lecciones humanas, la capacidad de cuestionar las condiciones establecidas de su vida” (p. 364). De algún modo, podría afirmarse que estas urbanizaciones están socavando la naturaleza de laboratorio social que Henri Lefebrve (1974) atribuía al espacio urbano, contribuyendo decisivamente -junto con las grandes infraestructuras viales y centros comerciales- a la fragmentación de la ciudad y, con ello, a la consolidación de un nuevo tipo de segregación socioespacial.

Sin embargo, más allá de los motivos y razones por las que los residentes deciden habitarlos ${ }^{1}$, hemos estimado pertinente reflexionar fundamentalmente acerca de la relación entre esos modos habitacionales y su espacio exterior de proximidad, y cómo esa gramática espacial condiciona la interpretación y ordenación que poseen los residentes de esas urbanizaciones con respecto a ese espacio exterior. Para ello hemos focalizado nuestra mirada en la ciudad colombiana de Cali y, en particular, en una de las nuevas centralidades espaciales que se están configurando. Nos referimos a esa área al sur de la ciudad que, destinada a las clases medias emergentes ${ }^{2}$ (estratos 4 y 5), está siendo producida bajo unas pautas espaciales paradigmáticas respecto de

$1 \longdiv { \text { Obviamente, una de las razones más objetivas para residir en ellas es el alto índice de inseguridad } }$ que registran muchas de las ciudades en América Latina (para más información, consultar http:// www.seguridadjusticiaypaz.org.mx/sala-de-prensa/1165-por-cuarto-ano-consecutivo-san-pedrosula-es-la-ciudad-mas-violenta-del-mundo); y, al mismo tiempo, cierta provisión de seguridad que pueden garantizar estos modos habitacionales.

2 Con clase media emergente nos referimos a la recomposición de ese sector amplio de la ciudadanía que, tras la crisis de los noventa y los ajustes neoliberales aplicados, pudieron invertir en capital cultural, procurarse un ascenso económico e interiorizar pautas de comportamiento constitutivas de la clase media urbanita: todo ello a pesar de la volatilidad y precariedad de las condiciones laborales (véase Sánchez, 2012). 
cómo entender la conexión entre urbanizaciones multifamiliares cerradas (UMC) ${ }^{3}$ y su entorno urbano.

Con tal fin, se ha aplicado una triangulación metodológica, que incorpora básicamente el método documental, la observación directa (durante ocho meses), las entrevistas de tipo informal y semiestructuradas (estas últimas a una muestra de catorce residentes y seis expertos), cuestionarios (aplicados a otros veinte residentes seleccionados aleatoriamente) y, por último, la técnica de los "mapas cognitivos" (en que participaron once residentes del barrio), todo ello fundamentalmente durante el año $2013^{4}$.

\section{Entre el orden simbólico del espacio y la práctica espacial}

Son Lindón, Aguilar y Hiernaux (2006) quienes exponen en un trabajo colectivo las diferentes nociones de espacio que han sido elaboradas desde el mundo académico. De ellas nos interesan, por una parte, las que hacen referencia al "espacio material producido", entendiéndolo como aquel espacio generado por las sociedades en función de su desarrollo tecnológico, de sus necesidades, de sus instituciones, de su estructura social, económica y política; y por otra, las que apuntan al "espacio vivido concebido" cuando este, siguiendo la opinión de Gumuchian, "deviene en objeto de estudio por los significados y valores que le son atribuidos" (citado en Lindón, Aguilar \& Hiernaux, 2006, p. 12). Estas dos nociones y su combinación -en definitiva, el modo particular de producción socioespacial- no solo conllevan, a nuestro entender, la materialización espacial de una sociedad, sino que también aluden - aplicando la categoría de "dominio étnico" de Lange (citado en Harvey, 1979)- a la forma que adquiere el espacio en la ciudad como símbolo de la cultura. En efecto, Henri Lefebvre (2013, p. 92) acuñó la categoría de "representaciones del espacio" para enfatizar la importancia de los significados dados por y para "el orden", y la de "espacio de las representaciones" para hacer referencia a los atribuidos desde la vida social, aquellos surgidos a ras de suelo. Se trata de una concepción retomada por la antropóloga Setha Low (1996), quien propone el término "culturalización del espacio" para imbricar las dos dimensiones constitutivas de la acción antrópica sobre el territorio: la producción y la construcción social del espacio. La primera entendida como aquellos factores políticos, técnicos y económicos que inciden en la configuración espacial; y la segunda, como el proceso de significación del lugar por sus usuarios y la puesta en circulación de esas imágenes para su posterior consumo.

En orden a evitar la conceptualización de los significados espaciales como un campo autónomo de prenociones subjetivas configuradas a partir de procesos de desanclajes no mediados ni por estructuras, posiciones o esquemas sociales, nos parece pertinente entender que esa dialéctica entre significados y espacio está sustentada en la apropiación y usos que los individuos despliegan sobre este último y que

3 En la clasificación realizada por Meyer y Bärh (2004), estas urbanizaciones corresponderían al tipo de condominios cerrados de clase media integrados en el perímetro urbano.

4 Este proyecto estuvo financiado con recursos propios del Centro de Investigación y Documentación Socioeconómica (CIDSE) de la Facultad de Ciencias Sociales y Económicas de la Universidad del Valle, Cali, Colombia. 
devienen en un proceso de reapropiación material y simbólica. En definitiva, dicha dialéctica nos remite a la noción de "espacio practicado" de Henri Lefebvre (2013), el cual puede ser definido como esa relación recíproca entre el lugar y la sociedad que, a través de la práctica, "lo produce lenta y serenamente dominándolo y apropiándose de él” (p. 92). Esta noción estaría vinculada a la capacidad de agencia individual a la que hacía referencia Pierre Mayol (2010, p. 6) cuando apelaba a la idea de "consumo espacial", puesto que en ella confluyen, de un lado, el "espacio privatizado particularizado", el cual está generado por el uso práctico cotidiano de ese espacio dado por el transeúnte; y, de otro, los "beneficios simbólicos esperados"; es decir, aquellas tácticas de apropiación espacial que pueden ser explicitadas mediante un "discurso de sentido", el cual puede ser expresado por los sujetos.

Retomando la idea de "consumo espacial”, según Pierre Mayol, este tendría como principal ámbito de análisis el barrio. Son sus límites, texturas y energías, bajo el tamiz de las técnicas de reconocimiento interiorizadas por los residentes, los que definen ese espacio. La selección de esta unidad de análisis no es contingente, por cuanto el barrio ha de contemplarse como una de las más relevantes instituciones intermedias, un lugar liminal y ambiguo donde se yuxtaponen lo externo y lo interno y que cumple una función de resocialización secundaria de gran valor, dado que activa y soporta procesos de reconocimiento e identificación entre pares, así como la posibilidad de constituir costumbres recíprocas. Al fin y al cabo, tomando prestada la definición de Dubet (2006), la función última de cualquier institución es la de instituir y socializar, porque "inscriben un orden simbólico y una cultura en la subjetividad de los individuos...” (p. 41). El barrio ha proporcionado y puede seguir proporcionando ese marco donde afiliar al individuo, donde educarlo.

Así pues, centrándonos en los barrios de las ciudades latinoamericanas y sus imaginarios, cabe resaltar que del mismo modo en que estos han sido objeto de prolijos análisis por parte del mundo académico, se ha tendido a privilegiar en particular dos escenarios confrontados (Hiernaux, 2007): uno radicado en las áreas deprimidas, marginalizadas y excluidas de dichas ciudades y que han sido extractadas bajo nociones como las de "favela", "villa miseria" o "callampas"; y un segundo ubicado en las figuras de los condominios cerrados o gated communities de estratos altos. En nuestra opinión, ambos proyectan entornos de segregación extrema que enfatizan la existencia de otredades anormalizadas y desviadas de la supuesta morfología urbanística inherente a toda ciudad planificada, lo que ha tendido a su vez a crear un cierto "sesgo reduccionista" (Sabatini, Cáceres \& Cerda, 2001) en el tratamiento de la segregación espacial de las ciudades latinoamericanas, al excluir casi sistemáticamente otros modos habitaciones percibidos como menos singulares o díscolos a los anteriormente aludidos.

Reconociendo, en cualquier caso, la validez en desvelar la naturaleza de esas lógicas simbólicas-espaciales y su interés académico, nuestra atención ha recaído en otras lógicas espaciales; es decir, en problematizar los nuevos modos de habitar de esa clase media emergente, que comienzan a visibilizarse en las urbes colombianas y, en general, en toda América Latina. En definitiva, cómo esas formas urbanísticas, a partir de su trama física y proyección ideacional, contribuyen a la configuración simbólica del espacio urbano interiorizada por sus residentes, pero también cómo 
estos residentes, a través de sus experiencias directas e indirectas, ordenan simbólicamente ese espacio y reconfiguran esos significados. Ambos procesos están contribuyendo, en nuestra opinión, a la generación de una nueva semántica de las ciudades latinoamericanas basada en una alta legibilidad del territorio y, al mismo tiempo, en una cierta pérdida o reducción de la experiencia espacial.

\section{El barrio La Hacienda: por una gramática de los dominios espaciales}

Situándonos en la ciudad colombiana de Cali, según las estimaciones de Rincón, Maldonado y Echeverri (2009), para el año 2006 se contabilizaban 1.478 de UMC, número que ha aumentado considerablemente en el último lustro como consecuencia de la expansión urbanística planificada hacia el sureste de Cali. Esta expansión se ha fundamentado en la edificación de urbanizaciones multifamiliares cerradas destinadas preferentemente a las emergentes clases medias y media-altas. Todo ello a pesar de las recomendaciones de los expertos por densificar la ciudad construida, como así se deja constancia en la propia Ley 152 de 1994 en su artículo $4^{\circ}$, donde se manifiesta la necesidad de impulsar la renovación y redensificación urbana. Esto se ha traducido, según la revista Metrocuadrado -especialista en la venta y publicidad de UMC y otros tipos de condominios cerrados- en que en esta zona sur de Cali (limitada entre la carrera 127 y la carrera 15), para el año 2013 se contabilizaban 104 proyectos de viviendas nuevas cuyo precio por metro cuadrado oscilaba entre los 42.915 y los 720.000 pesos colombianos; ello a diferencia de la zona oeste-centro, en la que solo se ofrecían 25 de tales proyectos (aunque el precio por metro cuadrado alcanzaba un máximo de 1.736 .000 pesos), de la zona oriente, con 7 proyectos, o la norte, en la que se localizaban 20 nuevos proyectos. Esto demuestra, siguiendo los planteamientos de David Harvey (1979), el establecimiento de una nueva centralidad en la ciudad cuyo objetivo es, una vez convertida en un área atractiva para la inversión inmobiliaria, propiciar la subida de renta y la obtención de plusvalía de un suelo hasta entonces no urbanizado. Tal proceso ha ido tendiendo hacia la financiarización de sus operaciones (De Mattos, 2007) debido, de un lado, a la confluencia de agentes autóctonos y alóctonos que apuestan por este tipo de inversiones inmobiliarias de corte financiero altamente especulativo, así como, de otro, al rol asumido por el Estado al justificar y facilitar un contexto favorable para dichas operaciones. Es por ello que, en opinión de Theodore, Peck y Neil (2009), las ciudades han ido convirtiéndose en uno de los principales objetos de las políticas neoliberales. En ellas se puede observar el principio básico del neoliberalismo basado en "destrucción” y "creación", cuyo objetivo "es movilizar espacios de la ciudad tanto para el crecimiento económico orientado al mercado, como para las prácticas de consumo de las elites, asegurando al mismo tiempo el orden y el control de las poblaciones excluidas" (p. 8). Por tanto, según los mismos autores, la reestructuración de los mercados de viviendas urbanas y la transformación del ambiente están llevado a la configuración de nuevas formas urbanas basadas en la "creación de comunidades enrejadas, enclaves urbanos y otros espacios de reproducción social 'purificados" (p. 9), destinados a las elites, pero también -afirmamos nosotros- a sectores medios de la sociedad. 
Así pues, uno de los barrios que forma parte de esta nueva centralidad y de esta lógica económica en Cali es La Hacienda, que puede ser tomado como máximo exponente y epítome de la articulación de las unidades residenciales y territoriales de nueva construcción dirigidas a las clases medias emergentes.

Centrándonos en esta vecindad, ella está situada en la zona noreste de la Comuna 17, entre la carrera 66 al norte, la calle 14 al este, la carrera 70 al sur y la Simón Bolívar al este. Sin duda, estas grandes vías encapsulan la vecindad en un área espacial perfectamente delimitada. Estimamos que su población puede ser de 5.759 residentes, la mayoría blancos o mestizos, de estratos 4 y 5 , es decir, clase media y media-alta, la mayoría de ellos propietarios de su vivienda. Destacan sobremanera en la configuración espacial del barrio dos zonas verdes. La principal se encuentra en las carreras 68 y 69 con las calles 14 y 16. Ambas mitades del parque están rodeadas de aproximadamente catorce urbanizaciones separadas por los consiguientes acerados y calzadas que conforman calles rectas y, en general, espaciosas; la mayoría de esas urbanizaciones es de entre seis a ocho plantas, aunque también existen dos unidades de viviendas unifamiliares. En su interior disponen de piscina, parqueadero, una pérgola, pero no zonas verdes o de juego infantil. Se ha de subrayar como elemento relevante la disposición de las terrazas o ventanas como espacios intracomunicativos entre lo interior y exterior. En la mayoría de las urbanizaciones, terrazas y ventanas se encuentran próximas a las calles y parques, aunque separadas por una franja espacial, acentuando con ello la lejanía entre el espacio exterior e interior. Del mismo modo, existen urbanizaciones cuyas fachadas principales están orientadas a espaldas de las zonas públicas, ubicación que potencia el "efecto pantalla" (Gelh, 2006) e imposibilita la activación de los mecanismos de control o monitorización social que devienen de la observación nítida y directa de los espacios exteriores por parte de los propios residentes. En cuanto a dotaciones y servicios, es en uno de sus límites, en la carrera 14 con la calle 66, donde se encuentra localizada la mayoría de pequeños locales y negocios que abastecen a los residentes cercanos, si bien en el último año se ha incrementado esta oferta. En total existían quince, entre los que destacan dos minimarkets, un restaurante vegetariano, una sala de Internet y una distribuidora de alimentos congelados. Junto a ellos se ha de destacar, como principal equipamiento, una iglesia adyacente al parque central del barrio.

Tomando como punto de partida la relación entre la capacidad de simbolización, la práctica espacial y la morfología urbanística, y aplicándolo a nuestro caso de estudio, la mayoría de los entrevistados declaró haber decidido residir en este barrio por cuestiones relativas a su "centralidad", "buena imagen" y "tranquilidad". De algún modo, estos nuevos residentes forman parte de esa cadena de producción y consumo de nuevas centralidades espaciales que comienza con la asignación a un área de unos usos múltiples (comerciales, residenciales y/o dotacionales), se les implementan algunas infraestructuras y, a continuación, se procede con la construcción de centros comerciales, la edificación de urbanizaciones y, tras ellos, los equipamientos. Sin embargo, los nuevos residentes no solo son receptores de esa estrategia planificadora, también ellos emplean tácticas en orden a evaluar los riesgos y potencialidades de sus nuevas residencias. Son activos en ese juego de oferta y demanda espacial, como se desprende de las palabras de algunos entrevistados: "En 
los últimos años todas las constructoras se han venido aquí, se ven buenos lotes..." (mujer, abogada, 28 años); "fuimos a buscar una zona de nuevo desarrollo urbanístico y toda esa parte estaba en construcción" (hombre, economista, 27 años); "esta es una muy buena habitación, por cuestiones de revalorización. Es un muy buen barrio" (hombre, economista, 28 ańos); "siempre me gustó esta zona, porque la veía como una zona de desarrollo urbanístico muy prometedora, en el sentido de tener un ambiente muy agradable para la familia, fácil acceso, cerca de las universidades, de los centros comerciales" (hombre, gerente, 52 años) o "en este momento el sitio de expansión y crecimiento es La Hacienda” (mujer, 34 años).

\section{Figura 1 Parque central del barrio La Hacienda}

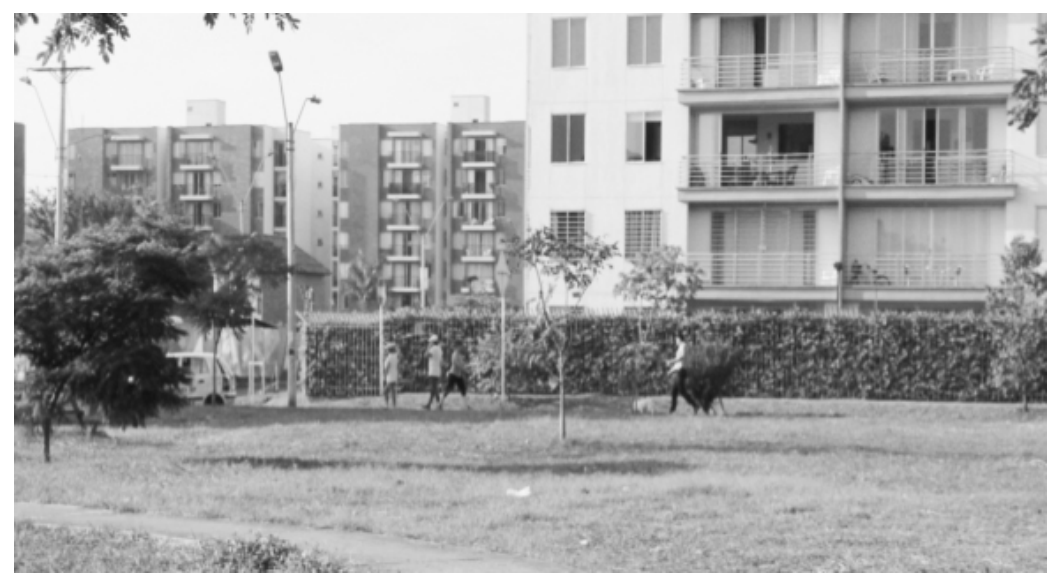

FUENTE FOTOGRAFÍA DE LOS AUTORES

Entre los aspectos evaluados, además de lo comentado anteriormente y de las propiedades particulares de las propias urbanizaciones (precio, distribución, servicios), también se alude a cuestiones más específicas, como la existencia de transporte público, salidas y accesos para el transporte motorizado, así como su carácter fundamentalmente residencial y, por tanto, la ausencia de comercios o locales de proximidad. Este distanciamiento con respecto a la posibilidad de que el barrio acoja actividades mixtas es sintomático. Varios de los entrevistados rehusaban dicha posibilidad, básicamente aludiendo a dos motivos. Un primero referente a la inseguridad, por cuanto, según ellos, la presencia de comercios y locales genera con su propia dinámica unas altas expectativas lucrativas para posibles delincuentes, lo que se convierte en un catalizador criminal. Un segundo motivo radica en la posibilidad de infracción de las normas cívicas (ruidos y suciedad) por parte de los comercios, especialmente los dedicados a la restauración, así como la incapacidad de la administración por controlar y hacer cumplir estas pautas, y sancionar su infracción. Es más, si bien una parte de los entrevistados había residido con anterioridad en barrios donde la proximidad de locales y comercios permitía, además de satisfacer ciertas necesidades inmediatas, la configuración de lazos de reconocimiento del otro -aunque fuesen vínculos débiles- y una parcial apropiación del entorno, prefieren 
conservar el actual perfil residencial y zonificado de su nuevo barrio. Esta preferencia residencial facilita la producción social del espacio por parte de las constructoras, y el control e intervención por parte de la administración pública. En el primer caso, al no estar las constructoras obligadas a la cesión de parte de los inmuebles para usos comerciales o terciarios, evitan una posible demora en la obtención de beneficios económicos, puesto que los locales son más difíciles de vender que las viviendas. Y en el caso de la administración pública, la preferencia por lo residencial le es conveniente frente a las dificultades que implica regular un sector complejo, por cuanto son múltiples las normativas que recaen sobre la actividades desarrolladas en comercios y locales (horario, sonidos, recogida de residuos o concesión de licencias).

Ahora bien, junto a la escasa disponibilidad de acceso a un comercio o locales de proximidad, se ha de aludir, tal y como Featherstone (1991) sugiere, a los nuevos modos de consumo y ocio posmodernos como factor también explicativo de las preferencias señaladas. Con la aparición de los supermercados y centros comerciales, el consumo de bienes básicos y recreativos -fundamentalmente de las clases medias emergentes- se ha reorganizado. Compras semanales, la optimización del tiempo de consumo al unirlo con el de ocio que posibilitan los centros comerciales, y la comodidad del autoservicio, han ido sacando de la programación diaria la asistencia a una cadena de locales y negocios barriales. En Cali esta tendencia se observa con la existencia de catorce grandes centros comerciales, más otros cinco que se prevén en los próximos años, la mayoría de ellos ubicados en las nuevas centralidades ( $E l$ Tiempo, 01/07/2013). Esto supone 19 metros cuadrados por habitante, así como el $7 \%$ de las compras realizadas sobre el total (El Pais, 09/06/2013)5.

Ese nuevo modo de consumo también ha impregnado incluso el comercio de proximidad, por cuanto se han ido reformulando otras modalidades de servicios, como son los domiciliarios. Pudimos observar cómo desayunos y almuerzos cocinados en los tres precarios puestos estacionarios contabilizados en el barrio La Hacienda, y a escasos metros de los domicilios, habían dispuesto de un servicio de mensajería para atender los pedidos telefónicos de residentes cercanos. Junto a ello, la gran mayoría de los entrevistados $(94 \%)^{6}$ reconocía que sus hábitos de consumo se desarrollaban en centros comerciales y supermercados relativamente próximos o, en su defecto, cuando era necesario satisfacer alguna necesidad momentánea, se solicitaba este tipo de servicio a domicilio. Se trata de un porcentaje muy superior al 23\% de los que reconocían que acudían a los negocios de proximidad al menos una vez por semana. Por tanto, esa tendencia rebaja el grado de sociabilidad que se genera a partir de la atracción ejercida por algunos improvisados puestos de venta, los cuales podrían ser considerados, tomando el concepto de Jacobs (2011, p. 96), "personajes públicos autodesignados" o "anclajes vecinales" (Del Campo, Flores \& García, 2009, p. 117), por cuanto son generadores de áreas de sociabilidad repetida

5 Para referencia a El Tiempo, véase http://www.eltiempo.com/archivo/documento/CMS12904036; para El Pais, http://www.elpais.com.co/elpais/economia/noticias/cali-le-abre-puertascentros-comerciales-le-mostramos-cuales

6 En total, la muestra entrevistada a partir de cuestionarios y/o entrevistas semiestructuradas fue de 34 residentes del barrio, siendo su perfil el siguiente: por sexo, $38 \%$ mujeres, $62 \%$ hombres; y por edad, 5,8\% menores de 17 años, $85 \%$ entre 18 y 59 ańos y $9 \%$ con 60 años o más. 
entre anónimos o conocidos, dotando al espacio de singularidad y reconocimiento. Sin embargo, esa tendencia no es óbice para que todas las mañanas se constituyan ciertas agrupaciones momentáneas de individuos alrededor de ellos, personas que a la par que consumen alimentos y bebidas, establecen fórmulas de interacción que van más allá de un simple saludo. Estos anclajes vecinales están entre los pocos mecanismos en el barrio que, situados en los vértices del parque, facilitan la construcción de un marco de reconocimiento vecinal.

\section{FIgURA 2 | Una de las calles del barrio La Hacienda}

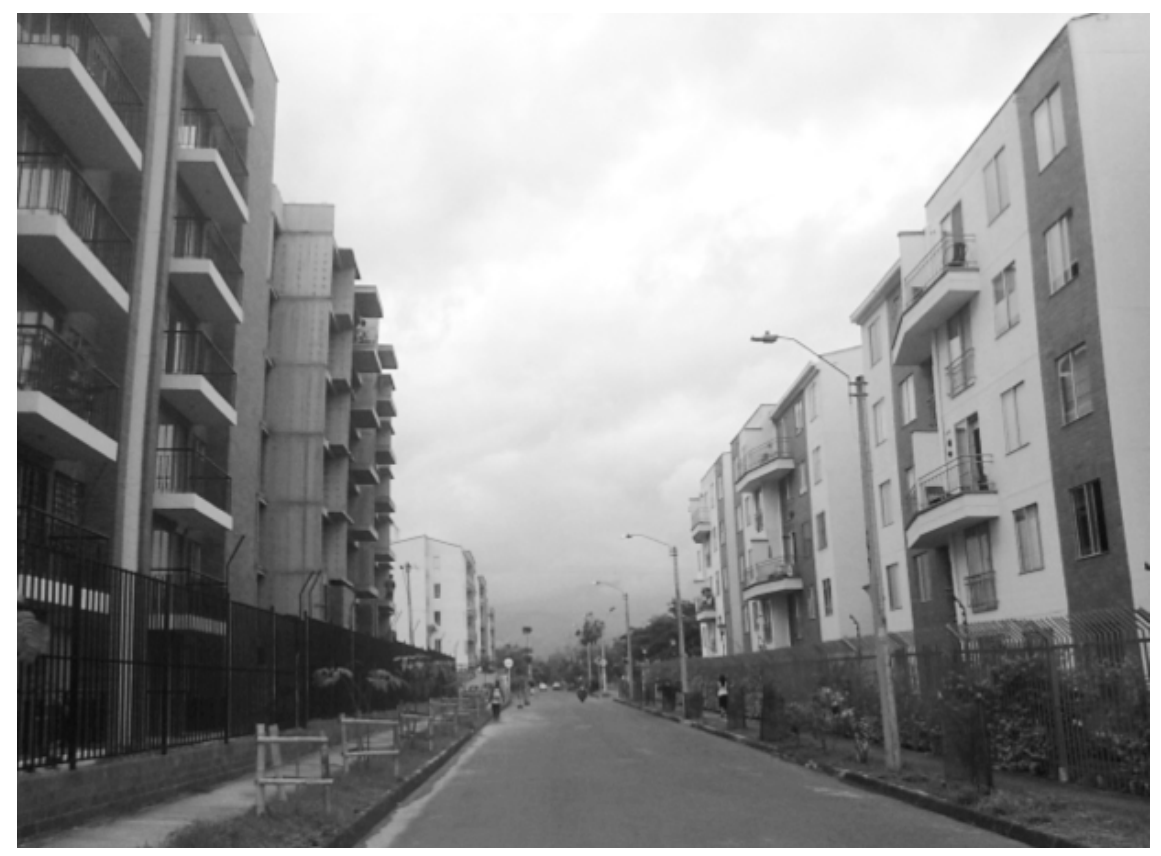

FUENTE FOTOGRAFÍA DE LOS AUTORES

\section{Legibilidad y reconocimiento simbólico del barrio La Hacienda}

Los "mapas cognitivos" como técnica de investigación fueron inicialmente aplicados desde la psicología ambiental (véase Holahan, 2002). Su función ha sido explicitar cómo los individuos perciben, codifican, construyen y representan el territorio con base tanto en su propia experiencia vital como en los imaginarios colectivos existentes sobre, en esta ocasión, algunas de las partes de la urbe. Para ello atendimos a algunos de los aspectos espaciales que, según Kevin Lynch (1960), guían la orientación espacial de los individuos. Nos referimos a los "nodos" (zonas estratégicas de confluencia), "hitos" (puntos observables y referenciales), "bordes" (elementos lineales que dividen o unen dos partes de la ciudad) y "sendas" (como las vías de tránsito). El objetivo de la aplicación de esta técnica radica en la representación gráfica, por parte de una muestra concreta de individuos, de la experiencia y percepción 
que tienen con respecto al espacio exterior próximo a sus residencias, tal y como lo llevaron a cabo Terence Lee (1970) para algunas ciudades inglesas y Florence Ladd (citado en Holahan, 2002) para un distrito de Boston con población mayoritariamente afroamericana. Es una representación espacial que no siempre se configura de un modo autónomo o desanclado de la práctica espacial de los usuarios; sino que, como muy bien lo formuló Pierre Mayol (2010), ambos aspectos -representación y práctica- suelen estar estrechamente ligados.

Finalmente, fueron once los entrevistados que aceptaron la realización de un mapa. Frente a las dudas que muchos de ellos mostraron acerca de su capacidad a la hora de esbozar uno, se les comentó que no era imprescindible poseer habilidades para el dibujo, sino que se trataba de cartografiar esquemáticamente dos cuestiones: los límites del barrio y aquellos lugares, objetos, personas u otros ítems que fueran importantes dentro de ese espacio. De los once, cinco eran residentes de la urbanización Nueva Hacienda, cuatro de Balcones del Limonar y dos de Parque del Alcázar. Centrándonos en los primeros, y a pesar de que su urbanización se encuentra separada de las del resto por la calle 16, dos de ellos curiosamente establecieron como su área (su barrio) las urbanizaciones y los espacios exteriores por el flanco sur hasta la calle 14, mientras que los otros dos solo incluyeron la calle 16 y la Simón Bolívar. De los siete restantes, seis limitaron la zona entre la calle 16 al este, la carrera 66 al norte, la calle 14 al oeste y la carrera 70 al sur. Solo uno de ellos incluyó el parque del Ingenio como elemente perteneciente al barrio. Como puede observarse, la mayoría entendió que las "sendas" (en esta ocasión las vías de tráfico) funcionaba como los "bordes" que delimitan las zonas. Solo existieron tres excepciones, en las que en dos de los casos fueron los inmuebles de las propias urbanizaciones los que asumía la función de límites, mientras solo uno estableció otro elemento (el parque del Ingenio) como el "borde" que instauraba la frontera al sur.

Con respecto a la configuración del barrio, el elemento que caracteriza los mapas de todos los participantes es la presencia de calles interiores como las principales "sendas". Son sin duda estas calles las que vertebran el propio barrio. Su trazado, con base en paralelas y perpendiculares, lo convierten en un territorio de fácil lectura, pero carente de atractivo peatonal.

Del mismo modo, atendiendo a la totalidad de los mapas, se desprende que el único ítem entre los "nodos" -aquellos puntos focales en el desarrollo de los mapas y que habitualmente asumen las formas de plazas o esquinas- que presentan los entrevistados es el parque dentro del entramado entre las calles 14 y 16. La ausencia de plazas, jardines u otro punto urbano que agencie esa función dota a este parque de una dimensión especial. Más que un "nodo", hablaríamos de un "hito"; incluso dos de los mapas de los residentes en la urbanización Balcones del Limonar iII hacen referencia a este espacio. Su carácter de "hito" también estaría sancionado por la descripción tan minuciosa de que es objeto. A diferencia del resto de los elementos, el parque es dibujado de un modo preciso: de los siete mapas de las urbanizaciones de La Hacienda, seis especifican los elementos que integran el parque, como son las canchas de básquetbol, de microfútbol, pista de trote, algunos bancos o los árboles. Es más, las pocas veces que aparecen personas, ellas están situadas en ese lugar. También en uno de los mapas se indica que es allí donde se asienta el grupo de 
jóvenes presuntamente consumidores de estupefacientes. En cuanto a los "hitos" como tales (edificios o lugares naturales referenciales), destacan la iglesia (9 de los 11 mapas), si bien no necesariamente es un espacio de uso cotidiano por parte de los entrevistados, y en menor medida el edificio hospitalario Clínica Amiga o Comfandi (5 de 11). Especialmente este edificio aparece en los mapas elaborados por los residentes de Balcones del Limonar iII. Para estos últimos, la clínica es el único referente arquitectónico visible que le ha sido dotado a su zona, junto a lo que ellos mismo denominan "potrero": con él se hacía referencia a esa segunda zona verde (localizada entre la carrera 68 y 69) que de facto no era más que un área baldía recubierta de vegetación en espera de ser reconvertida en zona verde o, en el mejor de los casos, en parque urbano, como así finalmente sucedió.

Destaca sobremanera cómo en la mayoría de los mapas (7 de 11) no se alude a ningún local o comercio de proximidad, ni tan siquiera a los puestos informales estacionarios de alimentos que diariamente se encuentran en una de las esquinas del parque y cercanos a la iglesia. De los cuatro restantes, en tres se plasma un local (en dos de ellos una panadería en la esquina entre la carrera 70 y calle 14 , y una pizzería en una esquina de la calle 66). Solo uno de los entrevistados localizó una variedad de locales comerciales con sus correspondientes emplazamientos, nombrando además el género de venta de cada uno. En total nombró siete establecimientos: una panadería y una tienda (sin especificar) en la calle 14 y en esta misma calle, pero más al oeste, un restaurante, una peluquería, un petshop, un spa y una academia de inglés.

FIGURAs 3 y 4 | Mapas cognitivos elaborados por dos residentes

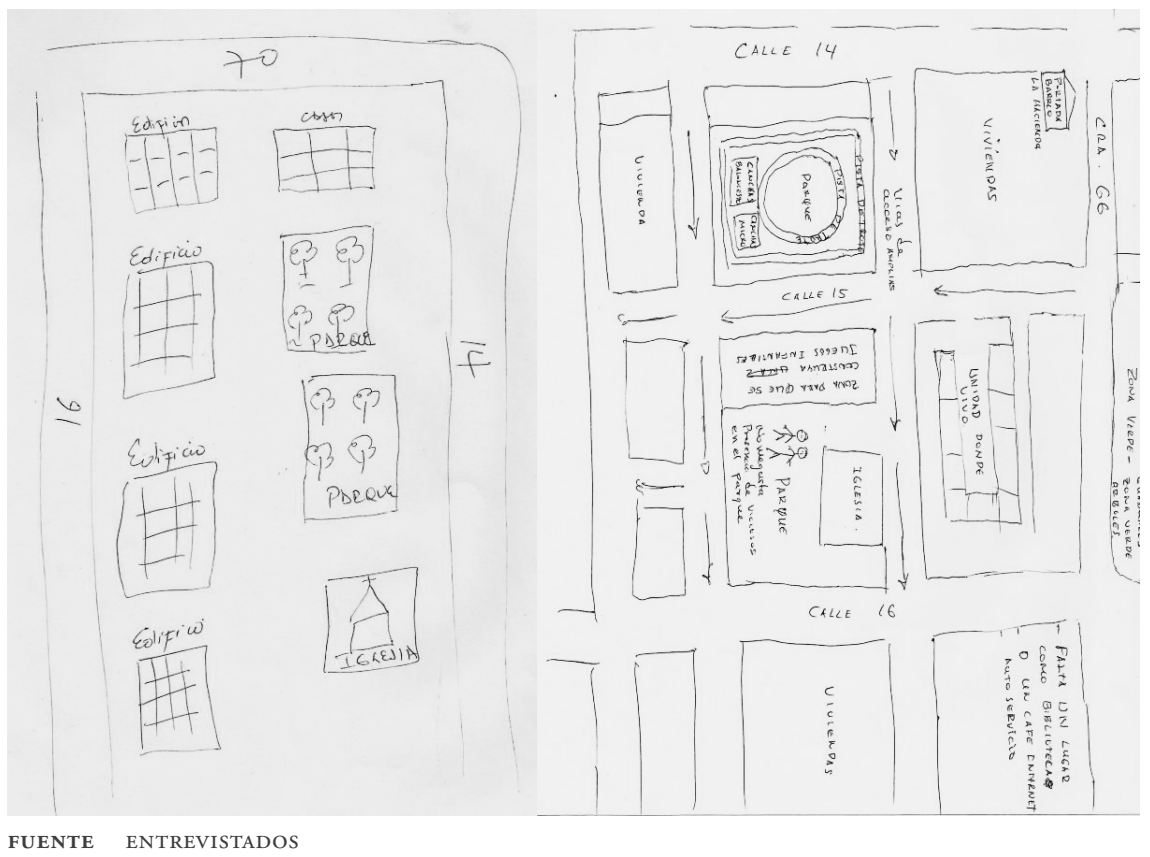



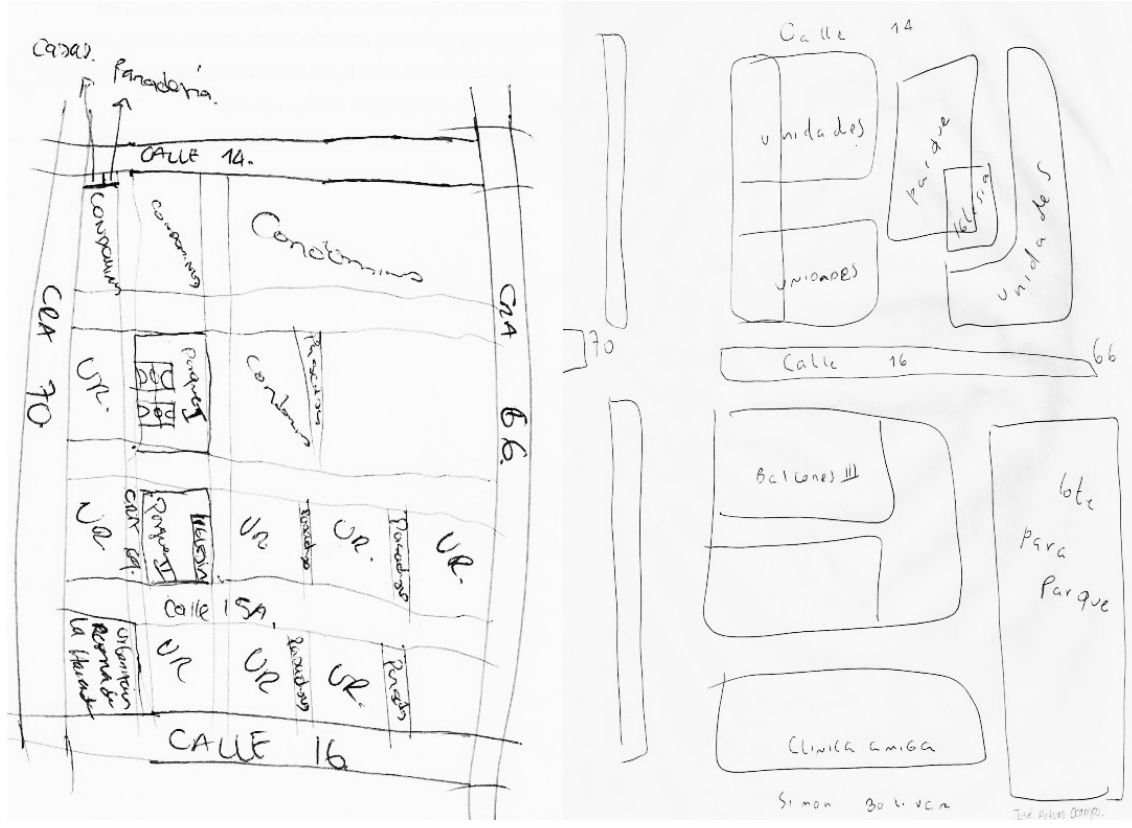

FIGURAS 5 y 6 | Mapas cognitivos elaborados por dos residentes

FUENTE ENTREVISTADOS

Los escasos elementos centrales identificados por los entrevistados (apenas el parque y la iglesia), así como el poco surtido de locales y negocios de proximidad ofrecidos, reflejan la consolidación de los nuevos modos de consumo básicos y de ocio, ubicados en los centros comerciales. Como ya se mostró, solo un $23 \%$ de los cuestionados reconocía comprar en el barrio. Esta circunstancia lleva a cuestionar los significados convencionales asignados a los conceptos de espacio exterior de proximidad y de lejanía, por cuanto estos no estarían ya definidos por la distancia física, sino más bien por el uso cotidiano dado. Como afirma Peter Hall (1997), nos encontramos en una etapa histórica donde se han roto los vínculos de proximidad a favor de los vínculos de conexión a diferentes niveles. De este modo, podría concluirse que los centros comerciales y otros locales fuera del ámbito barrial comienzan a ser sentidos más próximos que aquellos pocos locales (e incluso espacios abiertos) ubicados en la vecindad, pero que hasta estos momentos han sido incapaces de establecer vínculos sociales sólidos con los residentes. Así pues, junto con ese distanciamiento emotivo del barrio como territorio intermedio, se ha de destacar cómo esa simple composición urbanística basada en lo lineal facilita su reconocimiento espacial y ordenamiento simbólico, al mismo tiempo que reduce el grado de diversidad espacial existente y percibida por sus residentes. 


\section{Prácticas ambulantes y apropiación espacial en el barrio La Hacienda}

Teniendo en consideración lo anterior, podríamos interrogarnos acerca de cómo la política y el modelo urbanísticos están condicionando esa nueva semántica y si, más allá de esas políticas, existe correlación alguna entre un modo particular de ordenar simbólicamente el espacio y las prácticas individuales desplegadas en este. Para responder a tales cuestiones, se ha optado por rastrear, cartografiar y entender las actividades desplegadas por los residentes en el espacio exterior del barrio, en orden a determinar cómo se entrecruzan esas representacionales espaciales con las experiencias más corpóreas desempeñadas por esos mismos residentes. En definitiva, hemos recurrido a la "práctica espacial" de Lefebvre o al "espacio privatizado particularizado” de Pierre Mayol, pero siempre asociándolos a ese ordenamiento simbólico.

Como ya se expuso, es precisamente el parque localizado entre las calles 14 y 16 el lugar más señalado y valorado por los entrevistados, incluso independientemente del uso y frecuencia que cada uno de ellos le otorga. Las principales prácticas realizadas en él son las deportivas. Una de las más relevantes es el footing por el acerado que rodea ambas partes del parque y a veces a través de algunos de los recorridos improvisados por su interior. Lo interesante de esta práctica es su carácter individual, aunque en un modo gregario. No existe una convocatoria colectiva para su realización (como sí ocurre los fines de semana en el cercano parque del Ingenio para los talleres de deporte, en los que se dispone de horario, escenario y equipo), sino que los vecinos confluyen en el parque en algunos horarios determinados, convirtiendo esa actividad en altamente concurrida. Es cierto que esa confluencia está determinada por el horario laboral; sin embargo, también esa concentración humana conlleva una apropiación espacial entre pares, transformándose en una improvisada táctica de seguridad. Se produce un reconocimiento de ser vecino buen vecino- en un espacio particular y durante una misma acción, e incluso a partir del porte de una misma indumentaria, la deportiva. Por tanto, se sabe quién y por qué está ahí, aunque ese reconocimiento no cristaliza en interacciones fuertes y densas, ni en una interacción a partir del lenguaje corporal. Es decir, encontrarse en el mismo circuito deportivo de un modo repetitivo no genera el establecimiento de saludos -ni tan siquiera no verbales-, predominando con ello, y tomando la definición de Georg Simmel (1978), una "actitud blasé”. Por tanto, lo que impera es una cierta anomia, desinterés y encuentros no focalizados, tal y como lo entiende Joseph (1999): "formas de comunicación interpersonal que resultan de la simple copresencia" (p. 73). "Es triste lo que pasa en unidades de este tipo en Cali; es que uno pasea [caminado en el parque] y la gente no saluda. No sé si es porque no hay educación...", nos apuntaba uno de los entrevistados (hombre, directivo docente, 52 años).

Es necesario subrayar que, en su mayoría, los participantes en actividades en el parque son mujeres y hombres adultos, sin apenas distinción por sexo; por su parte, los niños utilizan fundamentalmente las canchas deportivas de forma colectiva en horario vespertino, una vez finalizado el escolar. Para ello se establece una cita entre los jóvenes de todas las urbanizaciones en un lugar particular y de allí parten a jugar al fútbol o baloncesto. Así nos lo describía nuestro informante de 13 años: "Como 
vamos a jugar a las canchas, empezamos a mantener amistad con otros muchachos de otras unidades. Quedamos en el centro del parque, que es como un punto estratégico de reunión...”.

Más allá del trotar, otra de las actividades individuales desplegadas en el parque es la salida con mascotas. Si bien ninguno de los entrevistados aludió a esto, hemos podido comprobar cómo esta acción implica un uso repetitivo -aunque no intensodel lugar y el establecimiento, siguiendo la propuesta de Erving Goffman (1981), de un rito secular de "introducción" y "definición de la situación", en el cual los individuos son conscientes de que acceden a un marco plausible de interacción cara a cara que ordena a los participantes en su forma de estar y en lo que se espera de ellos. Este marco propicia, a diferencia del constituido durante la práctica del footing, interacciones más cercanas y verbales durante los 15 o 20 minutos de su puesta en escena, tal y como nos indicaban algunos de nuestros informantes: "Si no tienes mascotas, no eres nadie" (mujer, estudiante, 21 años) o "es más fácil conocer al perro de su vecino que a su vecino” (hombre, directivo docente, 52 ańos).

Con respectos a acciones colectivas entre residentes, la mayoría de ellas se desarrolla en el espacio interior, en especial los Días de la Madre, del Padre, Halloween y la Novena de Aguinaldos. En esta última son los vecinos más próximos en una misma unidad los que se reúnen para celebrarla. En cualquier caso, parece que no existe una amplia gama de acciones realmente programadas en la que coincidan vecinos no ya del barrio, sino de la propia urbanización. No obstante, de nuevo el parque, en especial el tramo más urbanizado y polifuncional (en tanto que ofrece una mayor variedad de posibilidades de uso), es receptáculo de algunas actividades colectivas de corte barrial. Entre ellas, la organización de competiciones de baloncesto entre equipos representantes de las diferentes urbanizaciones, y la organización de un taller de patinaje infantil, constituyen plataformas de sociabilidad. En la primera instancia participan alrededor de treinta jóvenes y adultos, fundamentalmente hombres. En la segunda, alrededor de veinte personas (entre nińos y sus padres) posibilitan un uso intensivo del parque, cuyas consecuencias estriban en generar un marco de sociabilidad que va más allá de la propia acción, ya que otros vecinos aprovechan esa situación para apropiarse también del espacio, sea como meros espectadores, sea como transeúntes que pasean por el lugar. Estas son las únicas ocasiones en que ese espíritu de anomia, indiferencia, de relaciones no focalizadas es reconvertido en uno mucho más comunitario. Por tanto, son mecanismos que pueden contribuir a la conversión del capital social informal a uno más formal, frecuente y denso.

Si bien, y como puede constatarse, existen diferentes actividades desplegadas en el parque, fundamentalmente en una de sus partes, no parece darse cita en él una gran variedad de usuarios, circunstancia que propicia un uso del espacio exterior limitado en el tiempo y en sus formas. En efecto, algunos de los entrevistados afirmaban que sería deseable la activación de mecanismos con los que los vecinos pudieran apropiarse más de este lugar, el cual, por cierto, es el único espacio exterior de proximidad interpretado por los residentes como receptáculo que puede albergar vida social. De hecho, esta recomendación se planteó en una de las sesiones plenarias de una de las urbanizaciones del barrio. Más allá de algunos asaltos padecidos 
por residentes (para el año 2011 en la Comuna 17 se contabilizaron 589 robos $^{7}$ ), lo que subyacía a esta recomendación era la preocupación que suponía la presencia de un grupo de jóvenes sin identificar que, ocupando uno de los espacios laterales del parque, presumiblemente consumían y vendían estupefacientes. Sobre ellos recae cierto proceso de estigmatización y es a partir de ellos que se ha configurado un imaginario negativo asociado a la delincuencia, violencia y amenaza, convirtiendo el parque en una topofobia (O’Hare, 2007) temporal, en tanto que ese sentimiento se activa en los intervalos horarios en los que este grupo está presente.

Son numerosos los testimonios que mencionan esta circunstancia: "En uno de esos parques hay un problema. Hay reunión de marihuaneros. Ellos se han apoderado del parque..." (hombre, economista, 27 ańos); "pero hay una cosa que no me gusta y es que el parque atrae a muchos consumidores de sustancias psicoactivas. Esto obliga a uno a entrar a cierta hora y a salir a cierta hora" (hombre, directivo docente, 52 ańos); "hay una cosa que no me gusta: en el parque de allá a veces salen muchachos adultos a fumar marihuana. No los conocemos" (hombre, geólogo, 53 ańos) o "se ve movimiento en el parque... en las noches se pone como pesado. Llega gente a comprar o a vender droga" (hombre, economista, 28 años). Tales impresiones fueron corroboradas por uno de los administradores de una de las urbanizaciones al preguntarle por el principal problema que esgrimían los residentes de dicha urbanización: "El problema de robo de autos es un flagelo; frente a nuestra copropiedad, el ańo pasado robaron cinco carros. Otro problema es el parque, el cual es el sitio de fumadores y expendedores de droga". Podría subrayarse que estas opiniones se habían configurado a pesar de que la relación directa entre los entrevistados y este grupo había sido mínima. Es más, fue el entrevistado de menor edad quien matizaba la peligrosidad de ese grupo, puesto que son ellos (los usuarios de menor edad) quienes de un modo regular se ven obligados a coexistir con los segundos. La estrategia mutua que ambos grupos han establecido para una templada cohabitación pasa por el despliegue de -tomando prestado de nuevo el concepto de Isaac Joseph (1999) procedente de Erving Goffman- una "convivencia no focalizada".

En cualquier caso, lo que nos ofrecen esas tensiones socioespaciales, con sus respectivas preocupaciones y posibles estrategias de apropiación espacial, es un contexto donde analizar el llamado fenómeno de territorialización. Fueron los integrantes de la Escuela de Chicago como R. Park, E. W. Burgess y R. D. Mckenzie quienes por primera vez hicieron referencia a dicho fenómeno. Este puede ser definido como el proceso por el cual individuos o grupos de individuos se apropian -o intentan apropiarse- de un espacio, con tendencia a reclamar su exclusividad. En nuestro caso de estudio, ese proceso de territorialización ha cristalizado en la apropiación, por parte de ese grupo de jóvenes consumidores y expendedores de estupefacientes, de un espacio particular del parque y el intento de controlarlo a partir de la propia imagen negativa y estigmatizada que irradian, circunstancia que les facilita un uso casi exclusivo de esa zona. De hecho, velan por que no se produzcan injerencias en su territorio por parte de ningún vecino o extraño. Pero también ese proceso

Para más información consultar: http://www.cali.gov.co/observatorios/publicaciones/perfiles_ por_comunas_pub 
de apropiación es llevado a cabo por los propios vecinos, lo que intentan haciendo uso gregario, colectivo y a veces intensivo y solicitando tanto la organización de actividades colectivas como el aumento de la presencia policial. Con respecto a esto último, según uno de los administradores de una de las urbanizaciones, los vecinos se estaban reuniendo para solicitar la presencia de un Centro de Atención Inmediata (CAI) de la Policía Nacional en el parque, aunque la desconfianza de algunos residentes hacia esta institución ha obstaculizado hasta el momento la aportación económica necesaria para su definitiva instalación.

Con respecto a la segunda de las zonas verdes, la localizada en la calle 16 entre las carreras 69 y 68, muchos de nuestros entrevistados (especialmente los que residían cerca de ella) esperaban su pronta conversión en un parque, a la par que emitían una valorización muy negativa de ese espacio: "Lo que no me gusta es el lote que está enfrente de la unidad. En Urbanismo y en Desarrollo Territorial de la ciudad está proyectado para que sea parque. Es temporal, aunque llevamos tres ańos sin saber nada, pero ese es el proyecto" (mujer, 34 años); "y que hagan rápido el parque de atrás, le da inseguridad al entorno. No tiene visibilidad, la gente se aprovecha para esconderse y hacer de las suyas" (hombre, gerente de empresa, 58 ańos); "enfrente, es como peligroso, como no está construido... Uno no puede estar por ahî" (hombre, empresario, 53 años), "[yo cambiaría] el parque. Nos dijeron que a un ańo de llegar nos lo arreglarían, pero llevamos cuatro, y nada" (joven, estudiante, 18 años); o "por aquí atrás hay todavía un potrero y se ve monte. Es horrible” (mujer, ingeniera, 31 años).

Como puede interpretarse de las respuestas, una ineficiente producción social del espacio puede significar un obstáculo en su apropiación, es decir, en la acción por la cual el individuo transforma el espacio marcándolo simbólicamente y tomando conciencia y dominio de él (Vidal \& Urrutia, 2005). Tal obstáculo también puede terminar en que se asocie ese espacio con imágenes negativas, lo que implica su estigmatización y la pérdida de su valor social. Por otra parte, el lote de la urbanización que tarda en ser transformado en parque ejemplifica, si bien de una forma extrema, un modo de entender e intervenir en el espacio público que se ha ido consolidando en Cali. La administración local, a partir del artículo 343 del Plan de Ordenación Territorial (РОт) vigente en el ańo 2013, estipulaba la cesión obligatoria del $18 \%$ y del $3 \%$ del área bruta del predio para espacios públicos y equipamiento colectivo, respectivamente, aunque sin especificar normativamente la distribución ni la configuración espacial de la propia cesión. Esto ha podido suponer en ocasiones la constitución de una red de espacios periféricos excesivamente fragmentados / concentrados o monofuncionales de difícil alteración. Por otro lado, la producción y conservación de zonas verdes (a veces también con naturaleza de parque) supone menos coste de producción y conservación que si se apostara por jardines o plazas, a la par que se satisface las expectativas de un cierto discurso ambientalista urbano asociado a la obtención obligatoria de una cantidad de hectáreas verdes por metro cuadrado y por habitante . $^{8}$

Según la dirección del Plan de Ordenamiento Territorial de Cali, la cantidad de zonas verdes por habitante en dicha ciudad es de 2,46 metros cuadrados, cifra comparativamente más baja que la de Medellín, ciudad que cuenta con 3,8 metros cuadrados por persona, y la de Bogotá con 3,7 
Pensamos que estos dos factores han consolidado la presencia hegemónica de las zonas verdes en detrimento de las plazas y jardines. De hecho, en la Ficha Normativa Urbana del Рот (perteneciente al Polígono Normativo PCSO-PN-141-D del РОт), en la que se incluye La Hacienda junto a otros tres barrios, solo se menciona, en cuanto a la provisión de espacio público, la necesidad de configurar una estructura de parques sectoriales y, en menor medida, el arreglo en calles y avenidas. Si bien estos parques estarán dotados de andenes, senderos, zonas blandas y duras, arborización, amoblamiento y señalización, no se mencionaban otros posibles tipos de espacio, como plazas, plazoletas o jardines. Los únicos lugares urbanizados al sur de la ciudad que podrían ajustarse a un espíritu de plaza tradicional son aquellos promovidos por centros comerciales, como las popularmente conocidas "plaza de la fuente" y la del "reloj" en Unicentro, uno de los shopping centers más conocidos de la zona sur. Estos son los espacios que ofrecen dispositivos para la estadía, sin necesidad -en principio- de consumir, en un contexto urbanizado y similar a algunas plazas del centro de Cali o de barrios caleńos construidos durante la etapa colonial y republicana (Bonilla, 2012).

\section{Unidades multifamiliares cerradas: la consolidación de una nueva geografía simbólica}

Podría afirmarse que la consolidación y la expansión de las UMC en la ciudad de Cali es un hecho consolidado. Ello no solo conlleva el establecimiento de un modo habitacional particular, sino que también establece formas particulares de relaciones con $-\mathrm{y}$ apropiaciones de- el espacio exterior de proximidad. En esa producción social de la ciudad encarnada en muchos de los nuevos barrios (especialmente en el sur) intervienen la administración pública, que redacta y aplica normativas jurídicas relativas a esa producción; las constructoras y promotoras, a las cuales se les transfiere en última instancia la materialización de diseño urbano; y los nuevos residentes, quienes objetivan las potencialidades del barrio donde residirán y racionalizan sus preferencias a través de la búsqueda de "tranquilidad", "buena imagen" y "centralidad".

De este juego a tres bandas se han ido configurando nuevos barrios en los que la tensión entre el espacio interior y el exterior se resuelve mediante la fortificación de las urbanizaciones por medio de vallas y muros, que en ocasiones agudizan el "efecto pantalla" entre ambos dominios espaciales. Del mismo modo, el barrio es trazado a partir de tres coordenadas: "bordes" bien delimitados que encapsulan al vecindario; "sendas" a base de rectas fundamentalmente pensadas como vías de tránsito vehicular y no necesariamente para estadía peatonal; e "hitos", en este caso en forma de parque urbano, el cual es interpretado como el único espacio que puede albergar vida social y, por tanto, aquel que encarnaría los principios constitutivos de lo denominado como espacio público: es decir, el lugar inclusivo de libre acceso, universal y gratuito. El parque central del barrio analizado, y a diferencia de ese

(El Pais, 29-10-2012, en http://www.elpais.com.co/elpais/cali/noticias/cali-por-cada-ciudadanohay-246-metros-espacio-publico 
otro calificado de "potrero" por los mismos residentes (un verdadero no lugar augeriano), es apropiado tanto física como simbólicamente. Este proceso de apropiación es producido principalmente por la práctica deportiva. Esta es la táctica aplicada por los residentes para apropiarse de él, si bien no necesariamente supone el establecimiento de un marco plausible de sociabilidad variada, densa y, en particular, extensiva. En todo caso, son algunas actividades deportivas organizadas colectivamente, el paseo de las mascotas y la existencia de algunos "anclajes vecinales", los que contribuyen al establecimiento de ese marco. La función de sociabilidad recae en ellos, dado el repliegue de las emergentes clases medias a los espacios íntimos y privados, y la ausencia de espacios de proximidad planificados, tales como negocios, locales, centros recreativos y culturales que posibiliten una sólida urdimbre de vínculos sociales y procesos extensivos de reapropiación espacial en y con el entorno más próximo.

Así pues, las circunstancias de que las UMC se estén convirtiendo en las fórmulas urbanísticas hegemónicas de la "ciudad formal" de Cali, y en general de Colombia, así como de muchas otras ciudades de América Latina, si bien implica mayores y más altos recursos y umbrales de seguridad e intimidad, también están ocasionando una reducción y simplificación de las representaciones y experiencias espaciales de sus residentes. De este modo, podría afirmarse que este tipo de barrio se estaría desviando de las funciones institucionales y de espacio intermedio de resocialización secundaria, para configurarse en un territorio tendente al tránsito, a lo hermético y, por tanto, sin gran capacidad de generar reconocimiento mutuo entre residentes y, en general, entre todos sus usuarios.

\section{Referencias bibliográficas}

Bonilla, R. (2012). Modelos urbanísticos de Cali siglo xx. En J. B. Garzón Montenegro \& G. Loaiza Cano (Comps.), Historia de Cali Siglo XX. Tomo I: Espacio urbano (pp. 25-85). Cali: Universidad del Valle.

De Mattos, C. A. (2007). Globalización, negocios inmobiliarios y transformación urbana. Nueva Sociedad (212), 82-96. Disponible en http://nuso.org/revista/212/gobernar-laciudad/

Del Campo, A., Flores, M. \& García, A. (2009). Proceso de peatonalización y nueva sociabilidad en dos ciudades andaluzas (Málaga y Sevilla). Sevilla: Consejería de la Vivienda y de la Ordenación del Territorio de la Junta de Andalucía. Disponible en http://www. centrodeestudiosandaluces.es/datos/factoriaideas/ifo2_09.pdf

Dubet, F. (2006). El programa institucional. En F. Dubet, El declive de la institución. Profesiones, sujetos e individuos en la modernidad (pp. 29-62). Barcelona: Gedisa.

Featherstone, M. (1991). Consumer culture and postmodernism. Londres: Sage.

Gelh, J. (2006). La humanización de espacio urbano. La vida social entre los edificios. Barcelona: Reverte.

Goffman, E. (1981). La presentación de la persona en la vida cotidiana. Buenos Aires: Amorrortu. Gumuchian, H. (1991). Représentations et aménagement du territoire. París: Anthropos. 
Hall, P. (1997). Megacities, world cities and global cities. Conferencia pronunciada en febrero de 1997 en Rotterdam. Disponible en http://www.megacities.nl/lecture_1/lecture.html Harvey, D. (1979). Urbanismo y desigualdad social. Madrid: Siglo xxI editores.

Hiernaux, D. (2007). Los imaginarios urbanos: de la teoría y los aterrizajes en los estudios urbanos. EURE, 33(99), 17-30. http://dx.doi.org/10.4067/S0250-71612007000200003

Holahan, C. (2002). Psicología ambiental. Un enfoque general. México D.F.: Limusa.

Jacobs, J. (2011). Muerte y vida de las grandes ciudades. Madrid: Capitán Swing.

Janoschka, M. (2002). El nuevo modelo de la ciudad latinoamericana: fragmentación y privatización. EURE, 28(85), 11-29. http://dx.doi.org/10.4067/S025071612002008500002

Joseph, I. (1999). Erving Goffman y la microsociología. Madrid: Gedisa.

Lee, T. (1970). Urban neighborhood as a socio-spatial schema. Ekistics, 30(177), 119-129.

Lefebvre, H. (2013). La producción del espacio. Madrid: Capitán Swing.

Lefebvre, H. (1974). La revolución urbana. Madrid: Alianza Editorial.

Lindón, A., Aguilar, M. A. \& Hiernaux, D. (Eds.) (2006). Lugares e imaginarios en la metrópolis. Barcelona: Anthropos / México: Universidad Autónoma Metropolitana. Versión digitalizada en http://danielhiernaux.net/publicaciones/archivos/2006-C2.pdf

Low, S. (1996). Spatializing culture: The social production and social construction of public space in Costa Rica. American Ethnologist, 23(4), 861-887. doi: 10.1525/ ae.1996.23.4.02a00100

Lynch, K. (1960). The image of the city. Boston: MIT Press.

Mayol, P. (2010). Habitar. En M. de Certau, L. Giard \& P. Mayol (Eds.), La invención de lo cotidiano 2. Habitar, cocinar (pp. 3-132). México, D.F.: Universidad Iberoamericana.

Meyer, K. \& Bärh, J. (2004). La difusión de condominios en las metrópolis latinoamericanas. El ejemplo de Santiago de Chile. Revista de Geografia Norte Grande, (32), 39-53. Disponible en http://revistanortegrande.cl/archivos/32/03_32_2004.pdf

O'Hare, D. (2007). Not another Waikiki? Mobolizing topophilia and topophobia in coastal resort areas. En X. Ruan \& P. Hogben (Eds.), Topophilia and topophobia: Reflections on twentieth-century human habitat (pp. 185-201). Londres: Routledge.

onU-Habitat - Programa de las Naciones Unidas para los Asentamientos Humanos (2012). Estado de las ciudades de América Latina y el Caribe 2012. Rumbo a una nueva transición urbana. ONU-Habitat [online]. Disponible en http://www.onuhabitat.org/index. php?option=com_docman $\&$ Itemid $=538$

Rincón, T., Maldonado, M. E. \& Echeverri, M. L. (2009). Seguridad y convivencia en multifamiliares. Una mirada al encerramiento residencial. Cali: Facultad de Humanidades. Escuela de Trabajo Social / Universidad del Valle.

Roitman, S. (2003). Barrios cerrados y segregación social urbana. Scripta Nova. Revista electrónica de geografía y ciencias sociales, $7(146$ [118]). Disponible en http://www. ub.es/geocrit/sn/sn-146(118).html

Sabatini, F., Cáceres, G. \& Cerda, J. (2001). Segregación residencial en las principales ciudades chilenas: tendencias de las tres últimas décadas y posibles cursos de acción. EURE, 27(82), 21-42. http://dx.doi.org/10.4067/S0250-71612001008200002

Sánchez, J. F. (2012). Las clases medias profesionales en Cali. Relaciones y formas de protección. Cali: Universidad del Valle. 
Sassen, S. (2010). Preface: Urban gating: One instance of a larger development? En S. Bagaeen \& O. Uduku (Eds.), Gated communities. Social sustainability in contemporary and historical gated developments (pp. xii-xii). Londres / Washington: Earthscan.

Sennet, R. (1978). El declive del hombre público. Barcelona: Península.

Simmel, G. (1978). Las grandes ciudades y la vida intelectual. Discusión. Teorías sobre los sistemas sociales, $\mathrm{N}^{\circ} 2$, Barcelona: Barral.

Svampa, M. (2001). Los que ganaron. La vida en los countries y barrios privados. Buenos Aires: Biblos.

Theodore, N., Peck, J. \& Neil, B. (2009). Urbanismo neoliberal: la ciudad y el imperio de los mercados. Temas Sociales (66) (Santiago: Ediciones SUR), marzo, 1-11. Disponible en http://www.sitiosur.cl/r.php?id=898

Vidal, T. \& Urrutia, E. (2005). La apropiación del espacio: una propuesta teórica para comprender la vinculación entre las personas y los lugares. Anuario de Psicología, 36(3), 281-297. Disponible en http://www.raco.cat/index.php/anuariopsicologia/article/ viewFile/61819/81003 